\title{
Application of high resolution subTHz spectroscopy methods for analysing the content of grain odors
}

\author{
$\underline{\text { V.A. Anfertev }}{ }^{1}$, V. L. Vaks ${ }^{1}$, M.B. Chernyaeva ${ }^{1}$, E.G. Domracheva ${ }^{1}$, A.A. Gavrilova ${ }^{2}$, E.V. \\ Dabakhova $^{2}$
}

${ }^{1}$ IPM RAS, Nizhny Novgorod, Russia, anfertev@ipmras.ru

${ }^{2}$ NNSAA, Nizhny Novgorod, Russia

Terahertz high resolution transient spectroscopy on nonstationary effects (free damping polarization realizing in two modes - phase switching of radiation influenced on gas and fast frequency sweeping) and spectrometers, based on these methods (a wideband spectrometer, a marker detector for registering certain gases, a two-channel spectrometer with two independent radiation sources and one detector) are very interesting for analysis of multicomponent gas mixtures.[1] The possibility of use of terahertz high resolution transient spectroscopy in such agricultural (diagnostics of degree of corn mycosis based on analysis of corn odors), medical applications (veterinary diagnostics of diseases and pathology states of animals based on analysis of exhaled breath and vapors of biological liquids (urine, saliva)); monitoring the quality of foodstuff (meat, fish, poultry) based on analysis of its odors shows considerable promise.

In this work possibility of use of terahertz high resolution transient spectroscopy in such agricultural applications as analysis of corn odors for developing the methods of quality control and diagnostics is considered. The method was used to study "odors" of grain of new unique varieties: spring wheat "Sitara", winter wheat "Nemchinivskaya-17", barley "Binom" and oats "Arkhat". Researches of "odors" of different variety of grain were provided with subTHz transient backward wave oscillator based spectrometer in frequency range of 115-160 GHz which developed in IPM RAS. THz gas transient spectrometers based on transient gas absorption effects under radiation, which comes into resonance with molecular two-level quantum system in a shorter time than in the times of relaxation processes and transition radiation, when the

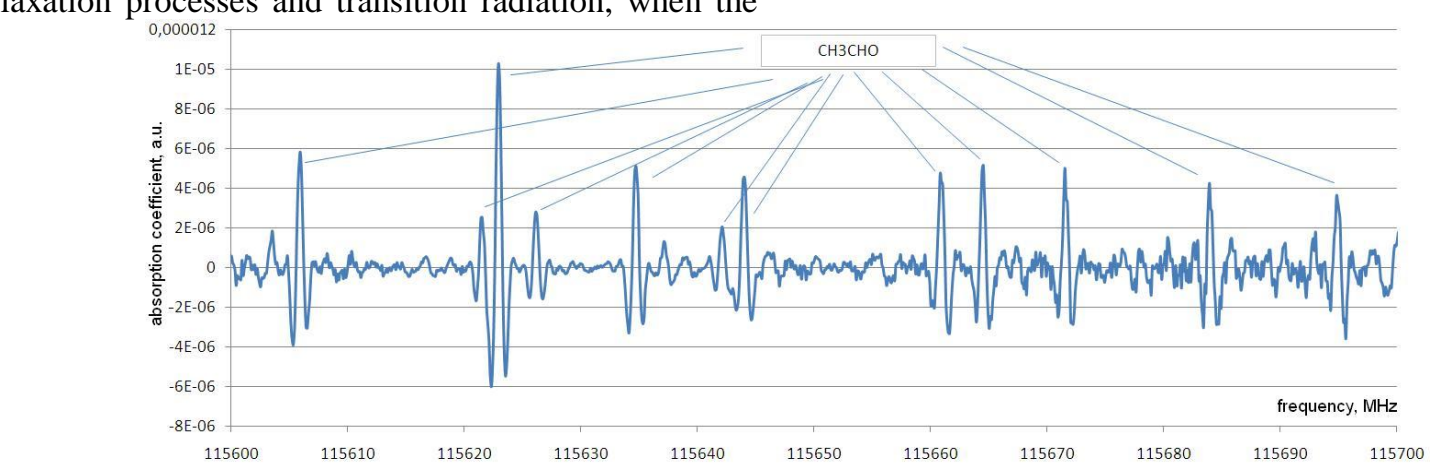

Fig. 1. The record of subTHz absorption spectrum in odor of barley ("Binom") sample after heating

radiation leaves resonance in a shorter time than in the relaxation times. The spectrometer has $1 \mathrm{kHz}$ frequency resolution and high frequency stability of radiation (1e-8). Quartz cell length of 1 meter was used as measurement volume. Grain (whole or ground) was placed in a flask, which was connected to a measuring gas cell. The cell was pumped to operating pressure with a vacuum pumping station «Pfeiffer Hi-Cube Eco $80 »$ to avoid unwanted gases and gas collisional broadening. For dehydration of the grain sample, vacuum drying with heating of the sample was carried out for some time. According to the developed measurement procedure, it is considered that to exclude the effect of water vapor on detecting trace concentrations of the mixture components, the pressure in the cell should be $1 \times 10 \mathrm{e}-3 \div 5 \times 10 \mathrm{e}-3$ mbar. After that, the heating of the flask containing the sample of grain continues.

The preliminary results on studying the grain odors composition of wheats, barley (Binom) and oats (Arkhat) are presented in the Table 1.

\begin{tabular}{|l|l|}
\hline Grain & Substances \\
\hline Winter wheat "Nemchi- & $\begin{array}{l}\text { Glycolaldehyde } \\
\text { (HCOCH2OH) }\end{array}$ \\
\cline { 2 - 2 } & Formic acid (HCOOH) \\
\hline Summer wheat (Sitara) & Formamide (NH2CHO) \\
\hline barley (Binom) & Acetaldehyde $(\mathrm{CH} 3 \mathrm{CHO})$ \\
\hline oats (Arkhat) & HCOCH2OH \\
\cline { 2 - 2 } & Ga-n-C3H7OH \\
\cline { 2 - 2 } & Acetaldehyde $(\mathrm{CH} 3 \mathrm{CHO})$ \\
\cline { 2 - 2 } & $\begin{array}{l}\mathrm{CH} 2(\mathrm{OH})-\mathrm{CH} 2-\mathrm{CH} 2(\mathrm{OH}) \\
\text { Propane-1,3-diol }\end{array}$ \\
\cline { 2 - 2 } & $\begin{array}{l}\mathrm{CH} 2(\mathrm{OH})-\mathrm{CH}(\mathrm{OH})-\mathrm{CH} 3 \\
\text { Propane-1,2-diol }\end{array}$ \\
\hline
\end{tabular}




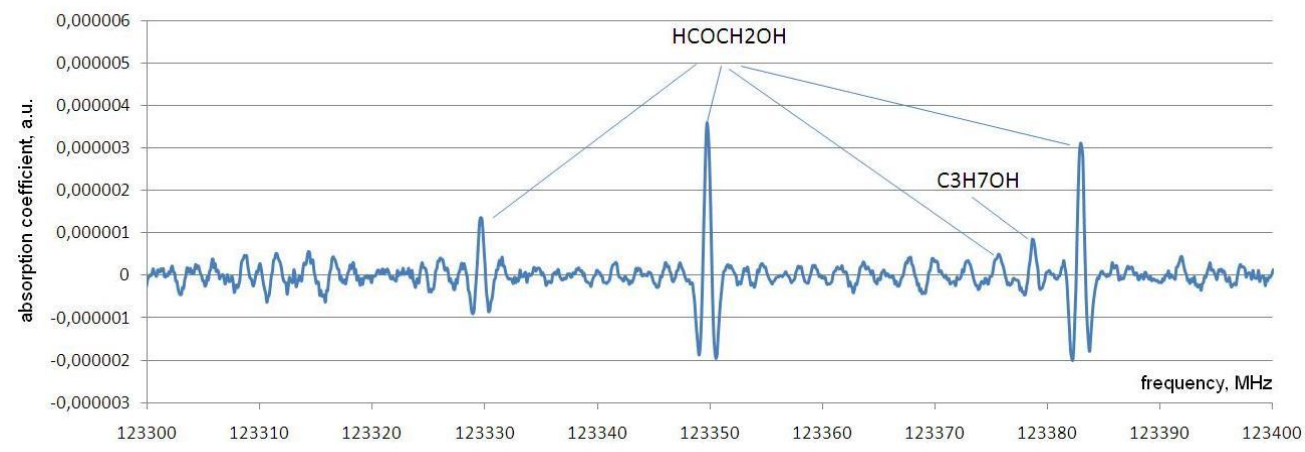

Fig. 2. The record of subTHz absorption spectrum in odor of oats ("Arkhat") sample after heating

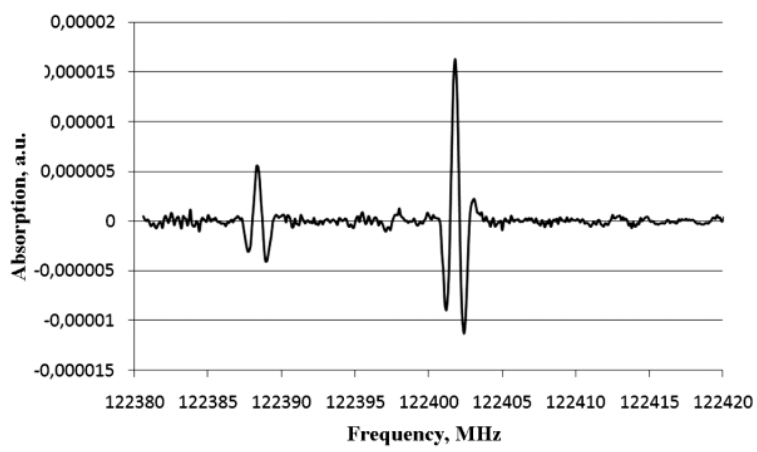

Fig. 3 The record of subTHz absorption spectrum of formamid in "odor" of summer wheat "Sitara"

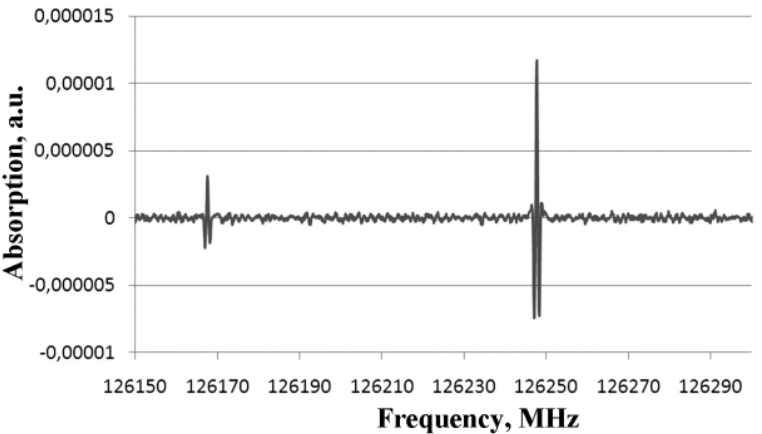

Fig. 4 The record of subTHz absorption spectrum of formamid in "odor" of summer wheat "Sitara"

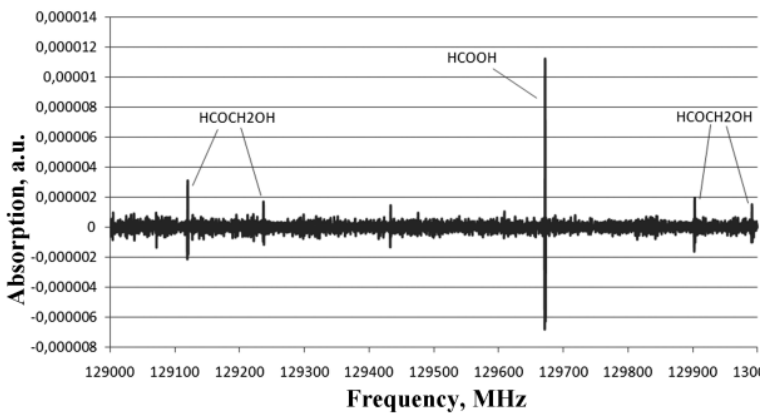

Fig. 5 The record of subTHz absorption spectrum of "odor" of winter wheat "Nemchinovskaya-17"

Fig. 3,4 shows the spectrum of formamide (NH2CHO) at $122.388 \mathrm{GHz} 122.402 \mathrm{GHz}, 126.168$ $\mathrm{GHz}$ and $126.248 \mathrm{GHz}[2,3]$, recorded when heated, when the grain sample begins to turn black, in the absorption spectra of the "odor" of "Sitara" wheat. The presence of formamide may be a consequence of the defeat of the grain by necrotrophic parasites. During evolution process, they developed a system of protection against toxic substances produced by the dying of infected cells, while one of the products of the transformation of toxic compounds is formamide.

The recording of the spectral region in the "odor" of winter wheat seeds of the variety "Nemchinovskaya-17" is shown in Fig. 5. A series of glycolaldehyde absorption lines $(\mathrm{HCOCH} 2 \mathrm{OH})$ at frequencies of $129120.22 \mathrm{MHz}, 129.236 \mathrm{GHz}, 129.902 \mathrm{GHz}$, $129.990 \mathrm{GHz}[2,3]$ and formic acid $(\mathrm{HCOOH})$ at the central frequency of $129.671 \mathrm{GHz}$ have been detected. The appearance of glycolaldehyde, apparently, is characteristic of a multicomponent gas mixture that appears during the heat treatment of plants or the selfheating of grain during storage. Thus, the appearance of glycolaldehyde was detected by the pyrolysis of cellulose [4], which is one of the main components of the cell walls of plants. The appearance of formic acid in the gas mixture of a sample of wheat during heat treatment requires additional studies.

The applicability of the method of subTHz transient spectroscopy for studying of grain of various cereal crops for the diagnosis of their condition and the detection of fungal diseases was shown.

This work was carried out in the framework of state targets N 0035-2014-0206 and financially supported by the Russian Foundation for Basic Research (grant N 18-42-520050 r_a_povoljie, N 17-00-00184 KOMFI, N18-52-16017)

\section{References}

1. Vaks, V.L., Domracheva, E.G., Chernyaeva, M.B., Pripolzin, S.I., Revin, L.S., Tretyakov. I.V., Anfertev, V.A., Yablokov, A.A., Methods and approaches of high resolution spectroscopy for analytical applications //Opt Quant Electron (2017) 49: 239

2.Pickett H. M. Submillimeter, Millimeter, and Microwave Spectral Line Catalog. JPL Molecular Spectroscopy// H. M. Pickett, E. A. Cohen, B. J. Drouin, J. C. Pearson California Institute of Technology. http://spec.jpl.nasa.gov/ftp/pub/catalog/catform.html, 2003

3. C. P. Endres, S. Schlemmer, P. Schilke, J. Stutzki, and H. S. P. Müller, The Cologne Database for Molecular Spectroscopy, CDMS, in the Virtual Atomic and Molecular Data Centre, VAMDC//J. Mol. Spectrosc. 327, 95-104 (2016)

4. Cole, Daniel Paul, "High resolution mass spectrometry for molecular characterization of pyrolysis products and kinetics" (2015). Graduate Theses and Dissertations. 14342. http://lib.dr.iastate.edu/etd/14342 